\title{
Reducing the Harmful Effects of Infrared Radiation on the Skin Using Bicosomes Incorporating $\boldsymbol{\beta}$-Carotene
}

\author{
Estibalitz Fernández ${ }^{a} \quad$ Lluís Fajaría $^{\text {Gelen Rodríguez }}{ }^{b}$ Mercedes Cócera $^{b}$ \\ Verónica Moner $^{a} \quad$ Lucyanna Barbosa-Barros $^{\mathrm{b}}$ Christina S. Kamma-Lorger ${ }^{c}$ \\ Alfonso de la Maza ${ }^{a}$ Olga López ${ }^{a}$

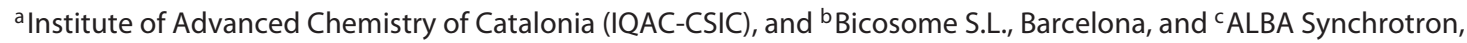 \\ Cerdanyola del Vallès, Spain
}

\section{Key Words}

Skin · Bicosomes · Infrared radiation · Collagen · Electron paramagnetic resonance $\cdot$ Small-angle X-ray scattering . Free radicals

\begin{abstract}
Aim: In this work the effect of infrared (IR) radiation, at temperatures between 25 and $30^{\circ} \mathrm{C}$, on the formation of free radicals (FRs) in the skin is studied. Additionally, the influence of IR radiation at high temperatures in the degradation of skin collagen is evaluated. In both experiments the protective effect against IR radiation of phospholipid nanostructures (bicosomes) incorporating $\beta$-carotene $(\mathrm{Bcb})$ is also evaluated. Methods: The formation of FRs in skin under IR exposure was measured near physiological temperatures $\left(25-30^{\circ} \mathrm{C}\right)$ using 5,5 -dimethyl-1-pyrroline-N-oxide spin trap and electron paramagnetic resonance (EPR) spectroscopy. The study of the collagen structure was performed by smallangle $X$-ray scattering using synchrotron radiation. Results: EPR results showed an increase in the hydroxyl radical in the irradiated skin compared to the native skin. The skin collagen was degraded by IR exposure at high temperatures of approximately $65^{\circ} \mathrm{C}$. The treatment with $\mathrm{Bcb}$ reduced the formation of FRs and kept the structure of collagen. Conclu-
\end{abstract}

sions: The formation of FRs by IR radiation does not depend on the increase of skin temperature. The decrease of FRs and the preservation of collagen fibers in the skin treated with $\mathrm{Bcb}$ indicate the potential of this lipid system to protect skin under IR exposure.

(c) 2016 S. Karger AG, Basel

\section{Introduction}

The skin is designed to protect the organism against injuries and works as a physical barrier against the external environment. Sunlight damages human skin, resulting in the formation of free radicals (FRs), which are in part responsible for erythema/edema, inflammation, photoaging, and skin disorders [1-4]. The negative effect of solar radiation on skin is usually associated with exposure to ultraviolet (UV) radiation [1-3]. UVB radiation is mainly responsible for DNA damage in the cells, and the pathway in which this DNA damage take place is discussed in many works [5].

However, skin is also exposed to infrared (IR) radiation. IR radiation can generate FRs in the skin, which, depending on the dose, are able to initiate a cascade of different signaling pathways, inducing therapeutic or

\section{KARGER}

E-Mail karger@karger.com

www.karger.com/spp (c) 2016 S. Karger AG, Basel

$1660-5527 / 16 / 0294-0169 \$ 39.50 / 0$
Estibalitz Fernández

Institute of Advanced Chemistry of Catalonia (IQAC-CSIC)

Jordi Girona 18-26

ES-08034 Barcelona (Spain)

E-Mail efptqt@ cid.csic.es 
pathological effects [4-9]. The FRs formed by IR radiation can be a quarter of the amount of FRs created by the UVB/UVA dose at the point of erythema [10]. Some studies relate FR formation to the increase in the temperature subsequent to IR radiation $[4,7,8,10]$. The question of whether the IR radiation induces the formation of FRs directly or whether it is a result of IR-induced heat shock is still open. This question is relevant as the skin is exposed daily to IR radiation from sunlight at physiological skin temperatures. The accurate measurement of FRs induced during IR exposure maintaining the sample at physiological temperatures could report interesting information about the direct action of this radiation avoiding the temperature effect.

IR radiation penetrates the epidermal and dermal layers of the skin and reaches deeper than UV; consequently, it can damage both skin compartments. The epidermis contains the stratum corneum, which is a physical barrier for the body [11]. The dermis is the second innermost layer and contains structural proteins such as collagen and elastin. Collagen accounts for around $75 \%$ of the total dry weight of skin and provides strength and integrity to the tissue [12]. This protein can be damaged by the effect of IR radiation by the overexpression of matrix metalloproteinases (MMP), which is activated by FRs $[4,5,13]$. Changes in the structure or organization of collagen are responsible for alterations in the skin morphology, such as discoloration, loss of elasticity, wrinkles, or impairment of barrier function $[12,14,15]$. The regularly staggered structure of collagen induces periodic variations of electron density visible by X-ray scattering as sharp Bragg peaks. The X-ray profile in healthy skin shows a characteristic d-spacing of around $65 \mathrm{~nm}$ and several reflections associated with this distance $[12,15]$. The position, intensity, and number of reflections of the typical axial periodicity of skin collagen change according to the effect of tissue physiology or physical conditions. These changes indicate a macromolecular disorganization of collagen, and consequently can indicate the degradation of the protein. Therefore, the study of the organization of skin collagen after IR radiation can also help to determine the potential effects of IR exposure on the skin.

In the current work the formation of FRs in the skin under IR exposure near physiological temperatures was evaluated using 5,5-dimethyl-1-pyrroline- $\mathrm{N}$-oxide (DMPO) spin trap and electron paramagnetic resonance (EPR) spectroscopy. The maximum skin temperature reached during the experiment was $30^{\circ} \mathrm{C}$. Therefore, the formation of FRs only by exposure to IR and without raising the temperature was investigated. Skin structural changes before and after IR exposure were also studied by small-angle X-ray scattering (SAXS) using synchrotron radiation. Additionally, a skin treatment was carried out with bicosomes incorporating $\beta$-carotene $(\mathrm{Bcb})$ to evaluate their protective effect on FR formation and on the structure of skin collagen against IR exposure.

Bicosomes are phospholipid assemblies formed by spherical vesicles of approximately 150-250 $\mathrm{nm}$ and discoidal structures of between 15 and $25 \mathrm{~nm}$ (online suppl. fig. 1; for all online suppl. material, see www. karger.com/doi/10.1159/000447015) [16, 17]. The combination of the lipid composition and the small size, as well as their morphological versatility, makes them very useful for various skin uses as carriers $[17,18]$. Both bicosomes and $\beta$-carotene have demonstrated ability to reduce FR formation in the skin $[9,17,19-21]$.

\section{Materials and Methods}

\section{Chemicals}

The chemicals used in this study are detailed in the online supplementary material.

\section{Preparation of $B c b$}

The preparation of bicosomes is explained in the online supplementary material. The concentration of each ingredient in the $\mathrm{Bcb}$ was the following (w/v \%):

DPPC 4.25\%, DHPC 0.75\%, $\beta$-carotene $0.01 \%$, PC: $8 \%$ and CHOL $2 \%$.

\section{Dynamic Light Scattering}

The hydrodynamic diameters of Bcb were determined by dynamic light scattering using a Zetasizer Nano ZS90 (Malvern Instruments, UK). The details of this technique are included in the online supplementary material [see also 22].

Skin Treatment with Bicosomes

The skin treatment with Bcb is explained in the online supplementary material.

\section{Electron Paramagnetic Resonance}

Native and treated skin samples were put into the quartz tissue cell of an EPR spectrometer (EMX-Plus 10/12 Brucker BioSpin spectrometer), with an X-band microwave bridge ( 9 GHz; EMX Premium X) and a 10-inch magnet (ER073) with a 12-kW power supply (ER083). More details about this technique and about DMPO treatment are included in the online supplementary material [see also 23].

\section{Small-Angle X-Ray Scattering}

The diffraction experiments were performed at NACD beamline, ALBA Synchrotron Light Source (Cerdanyola del Vallès, Spain), with a monochromatic beam of $12.4 \mathrm{KeV}$. The scattering patterns were recorded with an SAXS 2D detector ADSC 210r (ADSC, Poway, Calif., USA) with single exposed times of about 
Fig. 1. EPR spectra of skin before (black line; color in online version only) and after (red line) IR exposure. Dose: $777.6 \mathrm{~J} / \mathrm{cm}^{2}$.

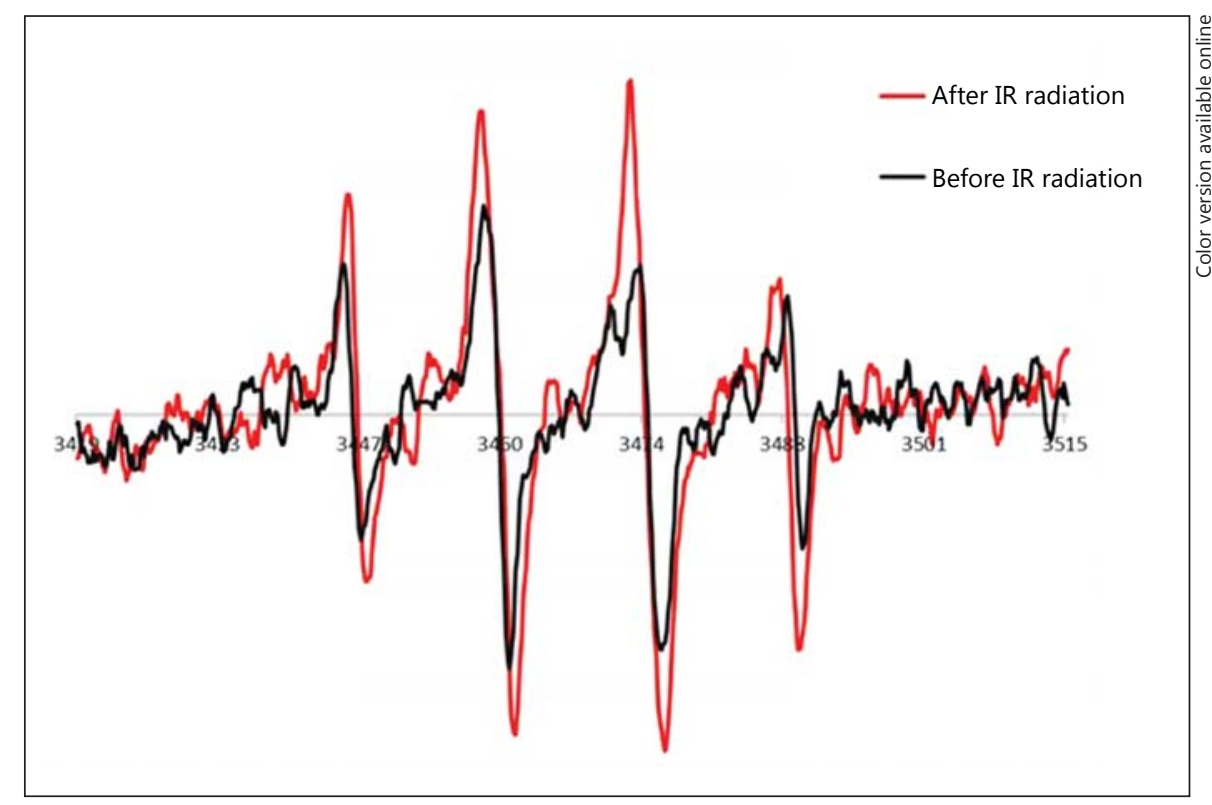

$3 \mathrm{~s}$. The distance from the sample to the detector was $6.4 \mathrm{~m}$. More details about this technique are included in the online supplementary material [see also 24].

\section{IR Exposure}

Skin samples were exposed to IR radiation using an IR lamp of $250 \mathrm{~W}$ (Philips Infrared BR I 25). The IR range emitted by the lamp is $800-1,500 \mathrm{~nm}$ (IR-A; see online suppl. fig. 2). Details of skin irradiation are included in the online supplementary material.

\section{Results}

\section{Bicosome Size}

The hydrodynamic diameters obtained using dynamic light scattering at $25^{\circ} \mathrm{C}$ for $\mathrm{Bcb}$ are shown in table 1 . For comparative purposes, the original size of the bicosomes without any incorporated molecule is also shown.

The size of the bicosomes without $\beta$-carotene was approximately $180 \mathrm{~nm}$ with the proportion of light scattered of approximately $85 \%$. The incorporation of $\beta$-carotene led to an increase in the particle size to approximately 250 $\mathrm{nm}$ and $85 \%$ of light scattered.

The increase in size of the Bcb could be due to the location of this lipophilic molecule in the bicosome structure [18]. Considering the low solubility in water of this antioxidant, this molecule is expected to be located in the lipophilic region of the bilayer of the bicosomes. Therefore, the incorporation of this lipophilic molecule inside the lipid bilayer of the bicosomes would promote a slight increase in the size of the nanostructures.

Protective Effects of Bicosomes with $\beta$-Carotene against IR
Table 1. Hydrodynamic diameters of the different bicosome systems and the proportion of the particle population analyzed by intensity of light scattering at $25^{\circ} \mathrm{C}$

\begin{tabular}{lll}
\hline Lipid system & $\begin{array}{l}\text { Hydrodynamic } \\
\text { diameters, } \\
n m\end{array}$ & $\begin{array}{l}\text { Intensity, } \\
\mathrm{nm}\end{array}$ \\
\hline Bicosomes & $180 \pm 20$ & 85 \\
Bcb & $250 \pm 30$ & 85 \\
\hline
\end{tabular}

Hydrodynamic diameter values are presented as means \pm standard deviations.

\section{FR Formation under IR Exposure}

The generation of FRs in pig skin samples was investigated by EPR using the DMPO probe, as it traps the FRs formed in the tissue. Figure 1 shows the spectra of native porcine skin before and after $120 \mathrm{~min}$ of IR radiation. Both spectra represent the symmetric spectral model of DMPO hydroxyl spin adduct (DMPO-OH ), and in general, in the current work the spectra that were obtained from all the skin samples showed similar patterns of DMPO-OH adduct $[25,26]$.

The spectrum intensity of the skin after IR exposure was higher than the spectrum intensity before IR radiation (fig. 1). This fact was a consequence of FR formation in the skin due to IR exposure and demonstrated the formation of FRs near physiological temperatures. 


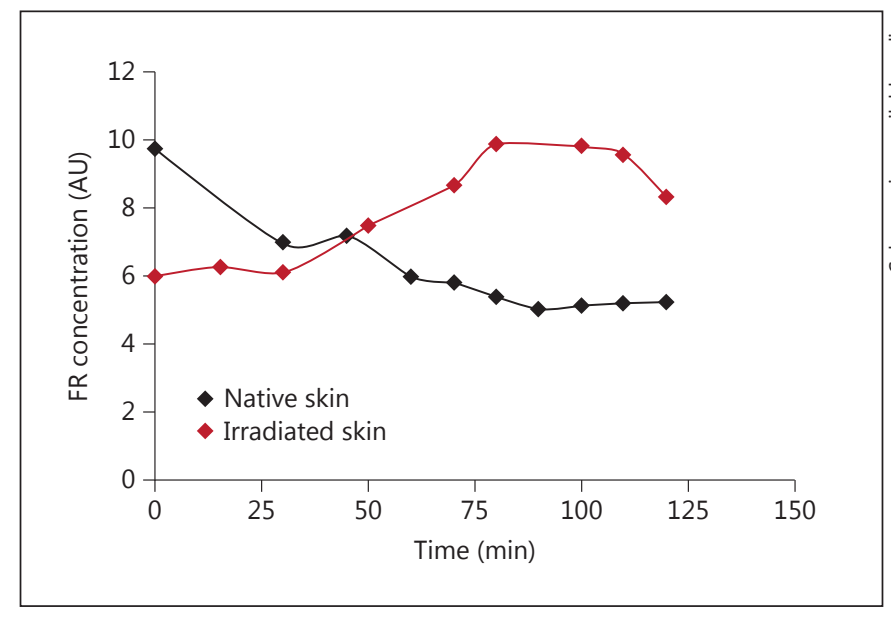

Fig. 2. FR concentration for native and irradiated skin at different times. Irradiation intensity: $0.108 \mathrm{~W} / \mathrm{cm}^{2}$.

It is known that the second integral value of the EPR spectrum is proportional to the FR concentration [23, 27]. Hence, for quantitative determination of the FR in the skin after IR radiation, the second integration values of the spectra at different irradiation times were calculated (fig. 2). This figure represents the kinetic evolution of FR concentration of native and IR-irradiated skin near physiological temperatures under IR exposure. The standard deviation of this data is between 1 and 2.5. The native skin showed a decrease in the FR concentration across time. This decay is a typical trend of these species and is a consequence of the destruction of the radicals $[28,29]$. The FR concentration in IR-irradiated skin was constant during the first minutes, but approximately 50 min later the FR concentration increased, leading to the conclusion that new FRs are formed. Finally, with approximately $80 \mathrm{~min}$ of irradiation the FR concentration was maintained. This fact demonstrated the capacity of IR radiation to form FRs in the skin when the skin temperature is around $25-30^{\circ} \mathrm{C}$.

The difference between the initial FR values could be due to the fact that the skin is a biological sample. Thus, even if all the skin pieces come from the same animal and have the same dimensions and treatment, these differences are expected.

The results obtained from the skin samples treated with $\mathrm{Bcb}$ are shown in fig. 3. The standard deviation of this data is between 1 and 2.5. Overall, the FR concentration was lower in skin treated with Bcb. In fact, the FR concentration in skin treated with $\mathrm{Bcb}$ was maintained during the $120 \mathrm{~min}$. After $75-80 \mathrm{~min}$ of IR radiation a

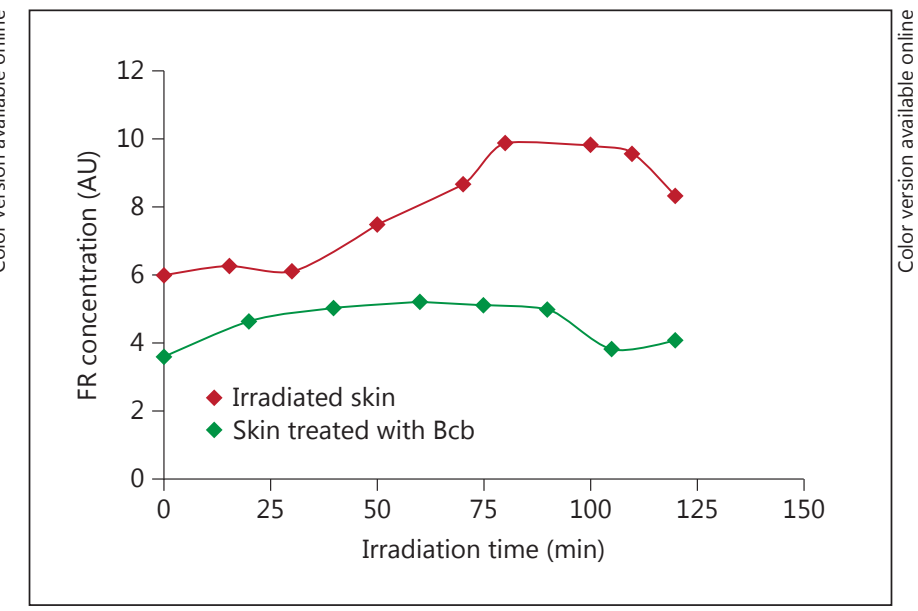

Fig. 3. FR concentration at different irradiation times for irradiated skin and for skin treated with Bcb. Irradiation intensity: 0.108 $\mathrm{W} / \mathrm{cm}^{2}$.

clear difference in the FR concentration was observed between the IR-irradiated skin and skin treated with $\mathrm{Bcb}$, which indicates a scavenging effect of this lipid system. Moreover, it is important to note that before irradiation (time $0 \mathrm{~min}$ ) the FR concentration was also lower in skin treated with $\mathrm{Bcb}$, indicating the neutralization of FR even in the absence of irradiation.

\section{Collagen Degradation under IR Exposure}

Establishing the Required Dose to Cause Skin

Collagen Degradation

It is known that high doses of IR radiation degrade the skin collagen, but to date the required IR dose that causes this degradation has not been clearly determined $[4,5$, 13]. Therefore, to evaluate the possible effect of Bcb protecting or repairing the negative effects on the skin collagen caused by IR radiation, it is necessary to establish the IR conditions to degrade the protein (see Materials and Methods).

The regular staggered structure of collagen induces periodic variations of electron density visible by $\mathrm{X}$-ray scattering as sharp Bragg peaks $[12,15]$. The study of these peaks can be used to evaluate the organization of the skin collagen.

Figure 4 shows the resulting SAXS profile of collagen when samples were irradiated adjusting the IR lamp at various distances from the sample $(10,15$, and $30 \mathrm{~cm})$ and irradiated for $30 \mathrm{~min}$ each time. The irradiation intensities for each distance correspond at $0.91,0.48$, and 0.16 $\mathrm{W} / \mathrm{cm}^{2}$, respectively. 


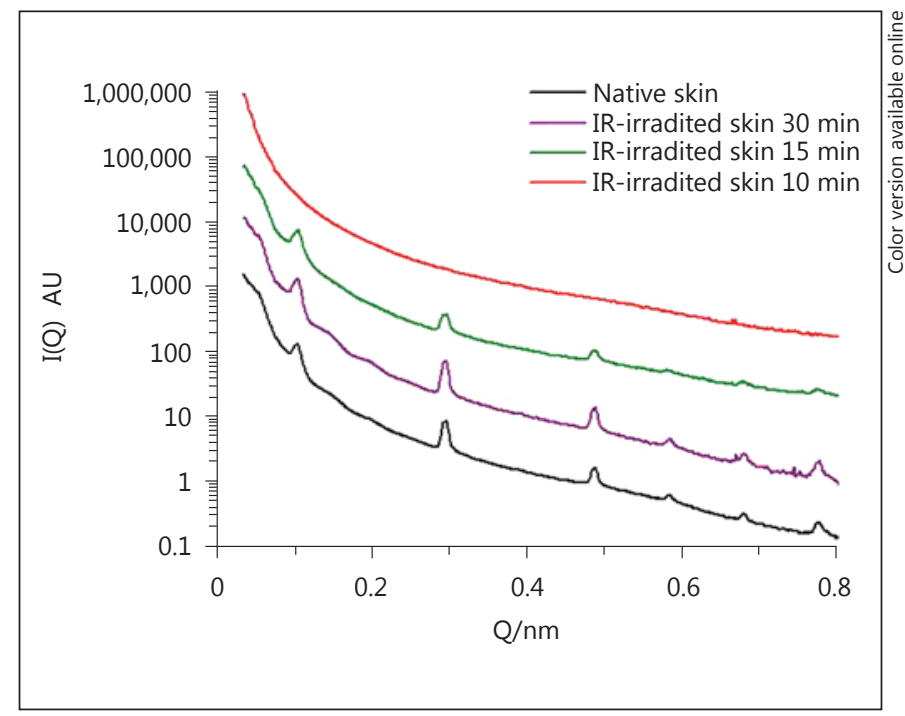

Fig. 4. SAXS profiles of native skin and IR-irradiated skin for 30 $\mathrm{min}$ at $30 \mathrm{~cm}$ (violet line; color in online version only), $15 \mathrm{~cm}$ (green line), and $10 \mathrm{~cm}$ (red line) from the source. The spectra were shifted on the vertical axis to allow visual comparison. IR: 800 $1,500 \mathrm{~nm}$.

When skin is irradiated at a skin-lamp distance of 30 and $15 \mathrm{~cm}$, the collagen peaks are clearly present, while at $10 \mathrm{~cm}$ the loss of the characteristic peaks of collagen indicated the disruption of the molecular disorganization of the protein. The skin temperature was $44^{\circ} \mathrm{C}$ when the skin-lamp distance was set at $30 \mathrm{~cm}, 68^{\circ} \mathrm{C}$ when the skinlamp distance was $15 \mathrm{~cm}$, and $75^{\circ} \mathrm{C}$ when the skin-lamp distance was $10 \mathrm{~cm}$. Therefore, in order to evaluate the possible protecting effect of $\mathrm{Bcb}$ on the skin, the skinlamp distance was fixed at $10 \mathrm{~cm}$. Then, while keeping the distance between the IR lamp and the sample fixed at 10 $\mathrm{cm}$, different irradiation times were applied to the skin while SAXS profiles were registered.

Figure 5 shows the gradual degradation of collagen of native skin exposed to IR at a fixed skin-lamp distance (10 $\mathrm{cm}$ ) over different periods of time. At this distance, the irradiation intensity delivered to the skin was $0.91 \mathrm{~W} /$ $\mathrm{cm}^{2}$, and the doses corresponding to these irradiation times were 273,546 , and $819 \mathrm{~J} / \mathrm{cm}^{2}$, respectively. After 5 and 10 min of irradiation the collagen peaks were still observed, but these peaks were shorter compared to those obtained from native skin. This fact could be due to the disorganization of collagen, which was a consequence of the degradation of the protein at this irradiation time. The skin temperature with the application of these doses was in the range of $60-65^{\circ} \mathrm{C}$. After $15 \mathrm{~min}$ of IR exposure

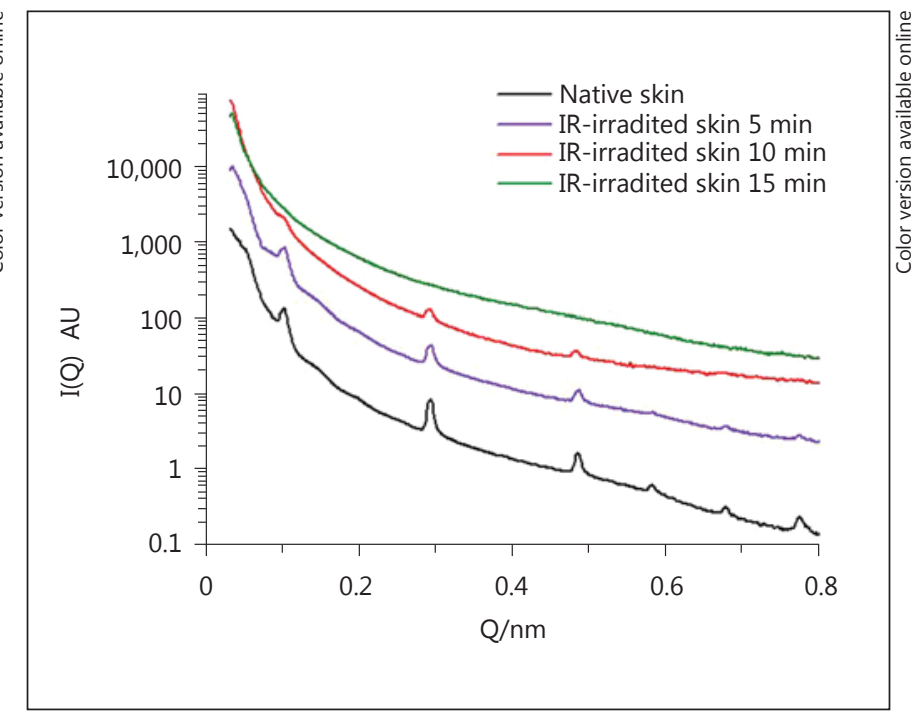

Fig. 5. SAXS profile of native skin and IR-irradiated skin at a skinlamp distance of $10 \mathrm{~cm}$ for $5 \mathrm{~min}$ (violet line; color in online version only), $10 \mathrm{~min}$ (red line), and $15 \mathrm{~min}$ (green line) showing the gradual collagen degradation. The spectra were shifted on the vertical axis to allow visual comparison. IR: $800-1,500 \mathrm{~nm}$.

the collagen peaks were not observed, indicating the total degradation of the protein. The skin temperature at this dose was approximately $70^{\circ} \mathrm{C}$.

With these results and in order to evaluate the possible effect of Bcb to protect the skin collagen, the skin-lamp distance was fixed at $10 \mathrm{~cm}$, and the irradiation time was fixed at $10 \mathrm{~min}$.

\section{Collagen Protection with Bcb}

The skin samples were treated with the Bcb system in order to evaluate its protective effect on skin collagen against IR exposure. Figure 6 shows the gradual degradation of collagen of native skin and skin treated with $\mathrm{Bcb}$ exposed to IR at a fixed skin-lamp distance $(10 \mathrm{~cm})$ for 10 $\mathrm{min}$. The characteristic collagen peaks in the X-ray profiles indicated an alteration in the molecular organization of collagen in the skin samples exposed to IR light in comparison with native skin, which demonstrated the damage produced in this protein at this irradiation time. The skin samples previously treated with $\mathrm{Bcb}$ and subjected to IR kept the X-ray profile with the characteristic features of collagen. This fact would evidence the preservation of collagen fibers of the skin treated with this system under IR exposure, indicating the potent efficacy of Bcb on collagen preservation. The skin temperature at this dose was approximately $60-65^{\circ} \mathrm{C}$. 


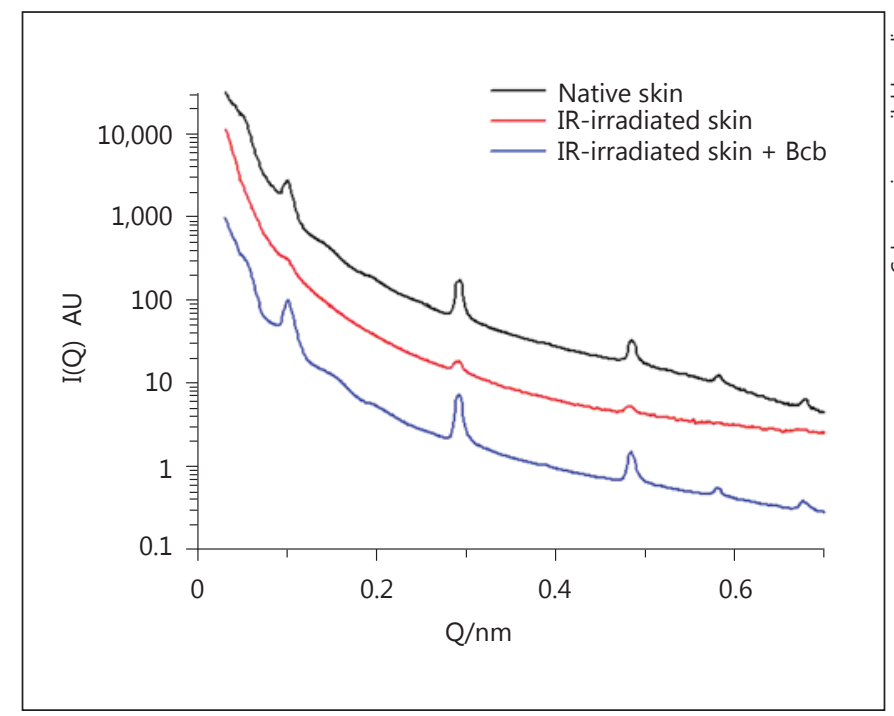

Fig. 6. SAXS profiles of different skin samples with the correspondent reflections of collagen. Native skin (black; color in online version only), IR-irradiated skin (red) and skin treated with Bcb (blue). The spectra were shifted on the vertical axis to allow visual comparison. IR: $800-1,500 \mathrm{~nm}$.

\section{Discussion}

\section{Influence of IR Radiation Forming FRs in the Skin}

The most known pathological effect of IR radiation on the skin (especially IR-A) is the overexpression of MMP molecules, which have a degrading effect on skin collagen $[4,10,13,30,31]$. Up to now, the formation of FRs by IR radiation is attributed mainly to the increase in skin temperature caused by this radiation [7-10,31], which could increase the temperature of the skin surface to $43^{\circ} \mathrm{C}$. However, the question of whether the IR radiation induces FR formation in the skin directly or whether it is a result of IR-induced heat shock is not clear to date. A recent study has shown that direct heat action to the skin does not increase the expression of MMP in the same manner as that observed with IR radiation [4]. This study demonstrates that the effect of heat produced by a water bath does not induce the same process as the IR radiation [4]. Therefore, it is important to evaluate the effect of the IR radiation independently of the heat produced by this type of radiation and, consequently, the potential of this effect to initiate therapeutic or pathological effects on the skin. The homemade device used in this study provides the optimal conditions to measure in situ the FR formation near physiological temperatures. The ventilator was able to remove the heat coming from the IR lamp, and therefore the temperature of the skin was maintained between $25-30^{\circ} \mathrm{C}$, allowing us to evaluate the effect of IR exposure on the skin.

Some studies claim that these FRs can induce therapeutic or pathological effects on the skin depending of the irradiation dose applied. At low doses $\left(1-10 \mathrm{~J} / \mathrm{cm}^{2}\right)$, IR radiation stimulates therapeutics effects, and at high doses $\left(>120 \mathrm{~J} / \mathrm{cm}^{2}\right)$ it stimulates pathological effects (approximately $1.5 \mathrm{~h}$ during direct sun exposure in summer time in Munich, Germany) [4]. In our experiments the irradiation intensity was $0.108 \mathrm{~W} / \mathrm{cm}^{2}$; thus, to achieve the dose of $120 \mathrm{~J} / \mathrm{cm}^{2} 18 \mathrm{~min}$ of IR exposure is necessary. As shown in this study, the FR concentration near physiological temperatures is similar to the FR concentration before IR exposure at this irradiation time (fig. 2, 3). Therefore, the possibility of this FR concentration causing pathological effects could be disregarded. It is likely that at the dose that was used, maintaining the temperatures between 25 and $30^{\circ} \mathrm{C}$, the IR energy is not enough to initiate negative effects on the skin. The increase of FR concentration near physiological temperatures is achieved at around $50 \mathrm{~min}$ of IR exposure, that is, when the dose is about $324 \mathrm{~J} / \mathrm{cm}^{2}$.

The doses used in this work are considerably higher than those used in other works in which FRs are formed. For instance, Zastrow et al. [10] detected FRs using smaller doses than in our work, but in those conditions the skin temperature was above $40^{\circ} \mathrm{C}$. Considering the important role of the temperature in the formation of FRs and the skin temperature below $30^{\circ} \mathrm{C}$ in our experiments, we needed to increase the IR dose to create FRs in the skin.

Further, it is important to consider that the minimum dose to increase the FR concentration is higher using IR radiation than using UV radiation. A previous study has shown FR formation in the skin exposed to UV radiation at doses around $25-30 \mathrm{~J} / \mathrm{cm}^{2}$ [17], which is noticeably lower than the dose of IR radiation used in this study. This fact is related to the difference in energy values between IR and UV radiation. The energy of UV radiation is higher than that of IR radiation; thus, high doses of IR radiation could be necessary to increase FR concentration in the skin.

In summary, the FR formation is possible near physiological temperatures during IR exposure, and it does not necessarily occur at high temperatures. Consequently, the initiation of different signaling pathways inducing therapeutic or pathological effects near physiological temperatures could be considered. 


\section{Stability of Skin Collagen under IR Radiation}

Skin collagen accounts for $75 \%$ of the dry weight of the tissue. This protein provides the elasticity to the skin and is responsible for the integrity of the tissue [12]. Collagen molecules are formed by three $\alpha$-polypeptide chains folded together to form a triple helical structure. The assembly between these triple helix molecules forms fibrillar groups in skin collagen, and the assembly between these fibrillar groups forms collagen fibers [12]. This protein can be damaged by the effect of IR radiation by the overexpression of MMP, which is activated by FRs $[4,13,31]$. Abnormalities of the collagen molecular structure affect the packing of collagen fibers in different tissues (skin, bone, breast, or tendon), which is linked to the pathological state of the tissue $[12,32]$. Therefore, the state of collagen of the skin could be evaluated by studying the height of the Bragg peaks obtained using the SAXS technique.

The degradation of skin collagen occurs at a minimum dose of $273 \mathrm{~J} / \mathrm{cm}^{2}$, when the skin temperature is around $60^{\circ} \mathrm{C}$. Total degradation occurs at a dose of $820 \mathrm{~J} / \mathrm{cm}^{2}$, when the skin temperature reaches up to $70^{\circ} \mathrm{C}$. Therefore, in order to cause degradation of skin collagen hard environmental conditions are necessary that are not normally part of everyday life. Nevertheless, the optimization of the conditions to degrade skin collagen helps to evaluate the effectiveness of various agents that aim to protect the protein structure.

In this work the collagen degradation by IR radiation at physiological temperatures has not been evaluated. In fact, given that collagen has a strong structure, we need to accelerate the degradation of this protein by the application of IR radiation at high temperatures. Darvin et al. [13] showed the degradation of collagen in vivo maintaining the physiological conditions of the skin using second-harmonic generation measurements. In that study the volunteers were exposed for a minimum of $2 \mathrm{~h}$ every day for 4 weeks. These conditions are not reproducible for our in vitro experiments. The in vitro conditions of the skin pieces would not maintain for 4 weeks, and considering the lack of the homeostatic process the skin could be damaged (dehydration and possible burning signals).

In our study, the reflections obtained at a distance of $30 \mathrm{~cm}$ during $30 \mathrm{~min}$ of irradiation indicate no degradation of the protein (fig. 4), although at these conditions the skin temperature was $44^{\circ} \mathrm{C}$. Therefore, we can assume the preservation of the collagen below this temperature (including the physiological temperature) and at this dose $\left(288 \mathrm{~J} / \mathrm{cm}^{2}\right)$. All in all, the degradation of skin collagen at physiological temperature and under IR radiation would be an interesting study in the future.

Protective Effects of Bicosomes with

$\beta$-Carotene against IR

\section{Skin Protection under IR Radiation by Bcb}

The application of Bcb on skin reduces FR formation and collagen degradation caused by IR radiation. This protection effect provided by Bcb could be associated with the properties of the $\beta$-carotene and with the characteristics of the bicosome system.

$\beta$-Carotene has been demonstrated to be an efficient antioxidant in lipid environments by trapping FRs or by quenching singlet oxygen radicals and protecting the collagen structure $[9,13,17,33,34]$. This antioxidant could act as a reducing agent of FR formation caused by IR radiation, and hence, the degradation of the collagen could be avoided.

In the bicosomes, the lipid molecules that form this system can also be responsible for the reduction of FRs in the skin. Lipid molecules absorb the IR light at different wavelengths [35], and bicosomes are formed exclusively by lipids. Thus, the different structures of the bicosomes (discoidal structures and spherical vesicles) absorb IR radiation. Additionally, in a previous work we demonstrated the antiradical effect of this system without antioxidants in skin exposed to UV-VIS radiation as a consequence of the light dispersion caused by the lipids forming bicosomes [17]. Therefore, we want to mention a possible protective effect of the bicosomes. It is probable that a synergistic effect between $\beta$-carotene and the bicosome structure could be responsible for the protective effect of the Bcb system.

To understand the protective effect of bicosomes, it is important to understand the interaction of this lipid system with the skin. The external vesicles, with a size of approximately $200 \mathrm{~nm}$, would not be able to penetrate through the superficial layer of the skin, the stratum corneum, and hence they remain on the skin surface in a similar way as described for other lipid vesicles [36]. Upon contact with the skin, the bilayer of the external vesicle of the bicosomes bursts, and the encapsulated disks (called bicelles) are released. Due to their small size and thickness, bicelles are able to penetrate into the skin [37]. Once incorporated into the stratum corneum, the bicelles increase in size as a consequence of the water content inside the tissue, and finally, they are retained into the tissue $[18,37,38]$. This increase involves a transition from bicelles to vesicles, and consequently, the bicelles are retained into the tissue (and also the $\beta$-carotene) [18, 37,38 ]. In fact, there are some studies related to the penetration of bicelles into the skin, which show the penetration of these systems deeper than the stratum corneum (around 30-40 $\mu \mathrm{m}$ ) [37, 39]. Therefore, bicosomes interact with the skin on the surface (by means of the external 
vesicle) and inside the tissue (by means of the internal bicelles), and in this way, the lipids and the $\beta$-carotene can remain on the surface and inside the skin as a reservoir of the tissue.

The IR radiation intensity that penetrates into the skin would be diminished due to the properties of the Bcb system, which would reduce the FR formation. Further, considering that IR radiation could penetrate as far as the dermis $[4,5,13]$, the penetration of this radiation would probably be deeper than the penetration of bicosomes. Nevertheless, bicosome components are retained in the skin. Then, due to the IR absorption properties of the lipids forming bicosomes and to the antioxidant properties of $\beta$-carotene, the radiation that arrives to the dermis would be reduced, which could contribute to the preservation of skin collagen. In this way, the protective effect of $\mathrm{Bcb}$ on deep-located collagen is based on a reduction of the IR radiation intensity that allows the dermis of the skin to be treated by bicosomes.

\section{Conclusions}

The IR device attached to the EPR spectrometer provides adequate conditions to perform FR measurements in the skin samples. The FR formation under IR exposure does not necessarily occur at high skin temperatures - it is also produced near physiological temperatures. Conse- quently, the initiation of different signaling pathways inducing therapeutic or pathological effects near physiological temperatures could be further investigated. High temperatures of approximately $65^{\circ} \mathrm{C}$ are needed to degrade skin collagen, which are not normally part of everyday life.

Treatment with $\mathrm{Bcb}$ reduces the formation of FRs in skin subjected to IR radiation and preserves the structure of collagen. This fact demonstrates the potent efficiency of bicosome systems in protecting the skin under IR exposure.

\section{Acknowledgment}

This work was supported by funds from CTQ 2013-44998-P.

\section{Statement of Ethics}

The skin used in this study comes from a sacrificed pig for medical experiments following the Guide for the Care and Use of Laboratory Animals published by the US National Institutes of Health (eighth edition, 2011).

\section{Disclosure Statement}

The authors declare no conflicts of interest.

\section{References}

1 Biniek K, Levi K, Dauskardt RH: Solar UV radiation reduces the barrier function of human skin. Proc Natl Acad Sci USA 2012;109: 17111-17116.

2 Holick MF: Sunlight, UV radiation, vitamin $\mathrm{D}$ and skin cancer: how much sunlight do we need? Adv Exp Med Biol 2008;624:1-15.

-3 Ichihashi M, Ueda M, Budiyanto A, Bito T, Oka M, Fukunaga M, Tsuru K, Horikawa T: UV-induced skin damage. Toxicology 2003; 189:21-39.

4 Akhalaya MY, Maksimov G, Rubin A, Lademann J, Darvin M: Molecular action mechanisms of solar infrared radiation and heat on human skin. Ageing Res Rev 2014;16:1-11.

5 Krutmann J, Morita A, Chung JH: Sun exposure: what molecular photodermatology tells us about its good and bad sides. J Invest Dermatol 2012;132:976-984.

6 Cho S, Shin MH, Kim YK, Seo J-E, Lee YM, Park C-H, Chung JH: Effects of infrared radiation and heat on human skin aging in vivo. J Investig Dermatol Symp Proc 2009;14:1519.
Darvin ME, Haag SF, Lademann J, Zastrow L, Sterry W, Meinke MC: Formation of free radicals in human skin during irradiation with infrared light. J Invest Dermatol 2010;130: 629-631.

-8 Darvin M, Haag S, Meinke M, Zastrow L, Sterry W, Lademann J: Radical production by infrared A irradiation in human tissue. Skin Pharmacol Physiol 2010;23:40-46.

-9 Darvin ME, Fluhr JW, Meinke MC, Zastrow L, Sterry W, Lademann J: Topical $\beta$-carotene protects against infra-red-light-induced free radicals. Exp Dermatol 2011;20:125-129.

10 Zastrow L, Groth N, Klein F, Kockott D, Lademann J, Renneberg R, Ferrero L: The missing link - light-induced (280-1,600 nm) free radical formation in human skin. Skin Pharmacol Physiol 2008;22:31-44.

11 Elias PM, Feingold KR: Skin Barrier. New York, Taylor \& Francis, 2006.

12 Costa M, Benseny-Cases N, Cócera M, Teixeira CV, Alsina M, Cladera J, López O, Fernández M, Sabés M: Diagnosis applications of non-crystalline diffraction of collagen fibres: breast cancer and skin diseases; in Ezquerra TA, Garcia-Gutierrez MC, Nogales A, Gomez M (eds): Applications of Synchrotron Light to Scattering and Diffraction in Materials and Life Sciences. Berlin/Heidelberg, Springer, 2009, pp 265-280.

13 Darvin ME, Richter H, Ahlberg S, Haag SF, Meinke MC, Le Quintrec D, Doucet O, Lademann J: Influence of sun exposure on the cutaneous collagen/elastin fibers and carotenoids: negative effects can be reduced by application of sunscreen. J Biophotonics 2014;7: 735-743.

14 Nam JJ, Lee KE, Kim YJ: Metal oxide区coating PMMA or talc as a new IR blocker inhibits IR冈induced decrease of collagens in human dermal fibroblasts. Int J Cosmet Sci 2015;37: 433-437.

15 Cocera M, Rodriguez G, Rubio L, BarbosaBarros L, Benseny-Cases N, Cladera J, Sabes M, Fauth F, de la Maza A, Lopez O: Characterisation of skin states by non-crystalline diffraction. Soft Matter 2011;7:86058611. 
16 Rodriguez G, Rubio L, Cocera M, Estelrich J, Pons R, de la Maza A, Lopez O: Application of bicellar systems on skin: diffusion and molecular organization effects. Langmuir 2010; 26:10578-10584.

17 Fernández E, Fajarí L, Rodríguez G, LópezIglesias C, Cócera M, Barbosa-Barros L, de la Maza A, López O: Bicelles and bicosomes as free radical scavengers in the skin. RSC Adv 2014;4:53109-53121.

- 18 Fernández E, Rodríguez G, Cócera M, Barbosa-Barros L, Alonso C, López-Iglesias C, Jawhari T, de la Maza A, López O: Advanced lipid systems containing $\beta$-carotene: stability under UV-VIS radiation and application on porcine skin in vitro. Phys Chem Chem Phys 2015; 17:18710-18721.

19 Darvin M, Zastrow L, Sterry W, Lademann J: Effect of supplemented and topically applied antioxidant substances on human tissue. Skin Pharmacol Physiol 2006;19:238-247.

20 Lademann J, Schanzer S, Meinke M, Sterry W, Darvin M: Interaction between carotenoids and free radicals in human skin. Skin Pharmacol Physiol 2011;24:238-244.

21 Lademann J, Patzelt A, Schanzer S, Richter H, Meinke M, Sterry W, Zastrow L, Doucet O, Vergou T, Darvin M: Uptake of antioxidants by natural nutrition and supplementation: pros and cons from the dermatological point of view. Skin Pharmacol Physiol 2011;24:269273.

22 Schmitz KS: An Introduction to Dynamic Light Scattering by Macromolecules. San Diego, Academic Press, 1990.

23 Stankowski J, Hilczer W: Introduction to Magnetic Resonance Spectroscopy. Warsaw, Wydawnictwo Naukowe PWN, 2005.
4 Bouwstra JA, Gooris GS, Bras W, Talsma H: Small angle X-ray scattering: possibilities and limitations in characterization of vesicles. Chem Phys Lipids 1993;64:83-98.

25 Buettner GR: Spin trapping: ESR parameters of spin adducts. Free Radic Biol Med 1987;3: 259-303.

26 Haywood R, Rogge F, Lee M: Protein, lipid, and DNA radicals to measure skin UVA damage and modulation by melanin. Free Radic Biol Med 2008;44:990-1000.

27 Eaton GR, Eaton SS, Barr DP, Weber RT: Quantitative EPR. Berlin, Springer Science \& Business Media, 2010.

28 Herrling T, Jung K, Fuchs J: The role of melanin as protector against free radicals in skin and its role as free radical indicator in hair. Spectrochim Acta A Mol Biomol Spectrosc 2008;69:1429-1435.

29 Plonka PM: Electron paramagnetic resonance as a unique tool for skin and hair research Exp Dermatol 2009;18:472-484.

30 Cho S, Lee MJ, Kim MS, Lee S, Kim YK, Lee $\mathrm{DH}$, Lee CW, Cho KH, Chung JH: Infrared plus visible light and heat from natural sunlight participate in the expression of MMPs and type I procollagen as well as infiltration of inflammatory cell in human skin in vivo. J Dermatol Sci 2008;50:123-133.

31 Schieke SM, Stege H, Kürten V, Grether-Beck $\mathrm{S}$, Sies H, Krutmann J: Infrared-A radiationinduced matrix metalloproteinase 1 expression is mediated through extracellular signalregulated kinase $1 / 2$ activation in human dermal fibroblasts. J Invest Dermatol 2002;119: 1323-1329.
32 Proksch E, Segger D, Degwert J, Schunck M, Zague V, Oesser S: Oral supplementation of specific collagen peptides has beneficial effects on human skin physiology: a doubleblind, placebo-controlled study. Skin Pharmacol Physiol 2014;27:47-55.

-33 Tsuchihashi H, Kigoshi M, Iwatsuki M, Niki E: Action of $\beta$-carotene as an antioxidant against lipid peroxidation. Arch Biochem Biophys 1995;323:137-147.

34 Mueller L, Boehm V: Antioxidant activity of $\beta$-carotene compounds in different in vitro assays. Molecules 2011;16:1055-1069.

35 Tamm LK, Tatulian SA: Infrared spectroscopy of proteins and peptides in lipid bilayers. Quart Rev Biophys 1997;30:365-429.

-36 Muller RH, Petersen RD, Hommoss A, Pardeike J: Nanostructured lipid carriers (NLC) in cosmetic dermal products. Adv Drug Deliv Rev 2007;59:522-530.

- 37 Rodríguez G, Barbosa-Barros L, Rubio L, Cócera M, Fernández-Campos F, Calpena A, Fernández E, De La Maza A, López O: Bicelles: new lipid nanosystems for dermatological applications. J Biomed Nanotech 2015;11: 282-290.

38 Rodriguez G, Barbosa-Barros L, Rubio L, Cocera M, Lopez-Iglesias C, de la Maza A, Lopez O: Bicellar systems as modifiers of skin lipid structure. Colloids Surf B Biointerfaces 2011; 84:390-394.

39 Fernández E, Rodríguez G, Hostachy S, Clède S, Cócera M, Sandt C, Lambert F, de la Maza A, Policar C, López O: A rhenium tris-carbonyl derivative as a model molecule for incorporation into phospholipid assemblies for skin applications. Colloids Surf B Biointerfaces 2015;131:102-107. 